\title{
Co-production of bioethanol and probiotic yeast biomass from agricultural feedstock: application of the rural biorefinery concept
}

\author{
Claire M Hull ${ }^{1}$, E. Joel Loveridge ${ }^{1}$, lain S Donnison ${ }^{2}$, Diane E Kelly ${ }^{1}$ and Steven L Kelly ${ }^{1 *}$
}

\begin{abstract}
Microbial biotechnology and biotransformations promise to diversify the scope of the biorefinery approach for the production of high-value products and biofuels from industrial, rural and municipal waste feedstocks. In addition to bio-based chemicals and metabolites, microbial biomass itself constitutes an obvious but overlooked by-product of existing biofermentation systems which warrants fuller attention. The probiotic yeast Saccharomyces boulardii is used to treat gastrointestinal disorders and marketed as a human health supplement. Despite its relatedness to S. cerevisiae that is employed widely in biotechnology, food and biofuel industries, the alternative applications of S. boulardii are not well studied. Using a biorefinery approach, we compared the bioethanol and biomass yields attainable from agriculturally-sourced grass juice using probiotic S. boulardii (strain MYA-769) and a commercial S. cerevisiae brewing strain (Turbo yeast). Maximum product yields for MYA-769 (39.18 [ \pm 2.42$] \mathrm{mg}$ ethanol $\mathrm{mL}^{-1}$ and $4.96[ \pm 0.15] \mathrm{g}$ dry weight $\left.\mathrm{L}^{-1}\right)$ compared closely to those of Turbo $\left(37.43[ \pm 1.99] \mathrm{mg} \mathrm{mL}^{-1}\right.$ and $4.78[ \pm 0.10] \mathrm{g} \mathrm{L}^{-1}$, respectively). Co-production, marketing and/or on-site utilisation of probiotic yeast biomass as a direct-fed microbial to improve livestock health represents a novel and viable prospect for rural biorefineries. Given emergent evidence to suggest that dietary yeast supplementations might also mitigate ruminant enteric methane emissions, the administration of probiotic yeast biomass could also offer an economically feasible way of reducing atmospheric $\mathrm{CH}_{4}$.
\end{abstract}

Keywords: Bioethanol; Biomass; Biorefinery; Cholesterol; Probiotic; Saccharomyces boulardii

\section{Introduction}

There is global impetus towards development of biorefineries that utilise industrial, rural and municipal waste for the production of bioenergy and marketable bio-based compounds. The biorefinery concept has been identified as a significant opportunity for rural economic development (Charlton et al. 2009; Leistritz and Hodur 2008; Sharma et al. 2011) and perennial ryegrass (Lolium perenne L.) is currently under investigation as a non-food crop that could be processed as feedstock in a rural biorefinery setting (Farrar et al. 2012). Production of biogas from ryegrass pulp (Kyazze et al. 2008) and bioethanol from grass juice (Martel et al. 2010; Martel et al. 2011) has already been achieved. Microbial biotechnology and metabolic engineering promises to

\footnotetext{
* Correspondence: S.L.Kelly@swansea.ac.uk

${ }^{1}$ Institute of Life Science, College of Medicine, Swansea University, Swansea SA2 8PP, Wales, UK

Full list of author information is available at the end of the article
}

diversify the application of the biorefinery approach for production of novel products and several 'designer yeast strains' capable of using polyfructose have been reported (Martel et al. 2011; Wang et al. 2011; Zhang et al. 2010). Nonetheless, yeast species that already have GRAS (generally regarded as safe) status remain readily applicable to biorefinery processes and novel uses for yeast biomass warrant consideration. In the present study, we investigate the co-production of bioethanol and probiotic yeast biomass from enzyme-pretreated grass juice (Martel et al. 2010).

In addition to its use in fermentation, food and biofuel industries, the brewing yeast Saccharomyces cerevisiae has several health applications. It is used as a protein supplement, immune enhancer and is employed as a vehicle for the introduction of dietary compounds as a commercialised health product (Moyad 2008). The yeast $S$. boulardii is administered for the treatment of gastrointestinal disorders (Buts 2009; Vandenplas et al. 2009; 
Zanello et al. 2009) and is currently the only commercially available probiotic yeast. The ability of $S$. boulardii to ferment ethanol has been documented (Gurgu et al. 2011) as have certain physiological and growth characteristics (Edwards-Ingram et al. 2007) including evidence that it can assimilate cholesterol (Chen et al. 2010; Psomas et al. 2003). However, despite its genetic relatedness to $S$. cerevisiae (Edwards-Ingram et al. 2004) and use as a human probiotic for over 50 years, the alternative applications of $S$. boulardii are not well studied. Given growing interest in the biotherapeutic properties of different yeasts (Foligne et al. 2010) there is now a clear incentive to develop and apply research knowledge about food grade yeasts.

The purpose of this study was to investigate if the co-production of bioethanol and probiotic yeast biomass is a feasible strategy for enhancing the productivity and value of rural biorefineries of the future. We sought to determine the potential bioethanol and yeast biomass yields attainable from agriculturally-sourced grass juice using $S$. boulardii (MYA-769) and a commercial S. cerevisiae brewing strain (Turbo yeast). Both strains of yeast are safe and the methodology reported in the present study (from feedstock extraction to product utilisation) compatible with land availability, rural land use patterns, current legislation and the existing technology base in the United Kingdom (Charlton et al. 2009; Farrar et al. 2012; Martel et al. 2010). The applications of yeast biomass as a feed additive and/or probiotic for livestock in the rural biorefinery setting are discussed.

\section{Materials and methods}

\section{Yeast strains and growth media}

Bioethanol and biomass co-production studies were undertaken using a commercial brewing strain of Saccharomyces cerevisiae (Turbo yeast; Gert Strand AB) and a probiotic strain of Saccharomyces boulardii (MYA-769; ATCC). Both were maintained at $30^{\circ} \mathrm{C}$ on yeast-peptone-dextrose (YPD) medium containing $(\mathrm{w} / \mathrm{v})$ : $2 \%$ glucose, $2 \%$ bacto peptone and $1 \%$ yeast extract ( $\pm 2 \%$ agar). All media components were supplied by Difco $^{\mathrm{TM}}$ (BBL/Difco Laboratories). All other chemicals were supplied by Sigma (Sigma-Aldrich Ltd) unless otherwise stated.

Grass juice (GJ) feedstock was extracted from ryegrass Lolium perenne supplied by the Institute of Biological, Environmental and Rural Sciences (IBERS, UK) (Martel et al. 2010). GJ was screened to remove large particulates, autoclaved $\left(121^{\circ} \mathrm{C}, 30 \mathrm{~min}\right)$ and frozen $\left(-80^{\circ} \mathrm{C}\right)$. When required for use as a growth and fermentation substrate, particle-free GJ was thawed and component fructans enzymatically hydrolysed using truncated $L$. paracasei $\beta$ fructosidase ( ${ }_{t}$ fosEp) as previously described (Martel et al. 2010). The concentration of free monosaccharides in untreated and enzyme pre-treated GJ + ${ }_{\mathrm{t}}$ fosEp was determined and the latter chosen for use as feedstock for all experimental work undertaken in the present study.

For sterol assimilation studies, cholesterol-supplemented glucose yeast minimal media $\left({ }_{\text {glc }} \mathrm{YM}^{+ \text {chol }}\right.$ ) containing $1.34 \%$ yeast nitrogen base without amino acids, $2 \%$ glucose and $10 \mu \mathrm{g} \mathrm{mL}{ }^{-1}$ cholesterol (final concentration) was prepared. Cholesterol was dissolved in 1:1 Tween 80:ethanol to give a $2 \mathrm{mg} \mathrm{mL}^{-1}$ stock and filter-sterilised prior to use.

\section{Sugar assay}

Sugar analyses were performed on 2500-fold diluted GJ and GJ $+{ }_{\mathrm{t}}$ fosEp in $100 \mathrm{mM}$ potassium phosphate, $\mathrm{pH}$ 7.0, containing $10 \mathrm{mM} \mathrm{MgSO}_{4}, 1 \mathrm{mM} \mathrm{NAD}{ }^{+}, 1.5 \mathrm{mM}$ ATP and 20 $\mathrm{U} \mathrm{mL}^{-1}$ Leuconostoc mesenteroides glucose-6-phosphate dehydrogenase (Worthington Biochemical Corporation). Concentrations of glucose, fructose, sucrose and fructan were determined from the changes in absorbance at $340 \mathrm{~nm}$ following sequential addition of $20 \mathrm{U} \mathrm{mL}^{-1} \mathrm{~S}$. cerevisiae hexokinase (Worthington Biochemical Corporation), $20 \mathrm{U} \mathrm{mL}^{-1}$ E. coli phosphoglucose isomerase (Megazyme International Ireland Ltd), $1.5 \mathrm{U} \mathrm{mL}^{-1} \mathrm{~S}$. cerevisiae sucrase/maltase (Megazyme International Ireland Ltd) and $150 \mu \mathrm{g}$ tosEp (purified as previously described Martel et al. 2010) respectively. Standards of glucose, fructose, sucrose and chicory inulin were used to calibrate the assay.

\section{Growth and fermentation studies}

Growth and fermentation experiments were performed in 100-well honeycomb microplates using a Bioscreen C (Oy Growth Curves Ab Ltd, Finland). Uniform starting $\left(\mathrm{t}_{0} \mathrm{~h}\right)$ culture densities were achieved by resuspending individual yeast colonies in GJ and diluting to obtain $5 \times 10^{5}$ cells $\mathrm{mL}^{-1}$ in GJ. Starting cultures were vortexed and aliquotted into Bioscreen wells (300 $\mu \mathrm{L}$ volumes). All experiments were incubated at $20^{\circ} \mathrm{C}$ for optimal bioethanol production as previously described (Martel et al. 2011) and optical density readings (at $600 \mathrm{~nm}$ ) taken every $45 \mathrm{~min}$. Data was exported from the Bioscreen in ASCII format prior to analysis using Excel (Microsoft Office 2003).

Growth parameters were derived using standard methodology. Briefly, $\triangle \mathrm{OD}$ values describe maximum OD - minimum OD; the lag phase is defined as the length of time a culture spends at $<10 \%$ of maximum OD; $\mathrm{T}_{1 / 2} \mathrm{Max}$ values are equivalent to the time taken to reach half the maximum increase in growth of a culture $(\Delta \mathrm{OD} \times 0.5)$. Fastest doubling times $(\mathrm{DT})$ were estimated by dividing the natural logarithm of 2 by the fastest culture growth rates $(\mu)$, where $\mu$ is the gradient of the linear trend line fitted to log-transformed OD data. 
Screening of experimental cultures for bacterial contamination and observations of the cell morphology of both yeast strains were made using a Nikon Eclipse E600 microscope.

\section{Bioethanol and biomass}

At specific time intervals $\left(t_{0} h, t_{24} h, t_{48} h, t_{72} h, t_{96} h t_{100} h\right.$ and $t_{124} h$ ) Bioscreen measurements were suspended and a $10 \mu \mathrm{L}$ volume of culture supernatant removed from representative experimental wells. These $10 \mu \mathrm{L}$ volumes were immediately diluted (10-, 100- and 1000-fold) with distilled water and frozen for subsequent ethanol analysis. Ethanol determinations were made using a spectrophotometric assay kit (K-ETOH 11/06; Megazyme Ltd) according to manufacturer's instructions. For biomass yield estimations ( $\mathrm{g}$ dry weight $\mathrm{L}^{-1}$ ), the contents of 10 unsampled Bioscreen wells were pooled at $t_{124} \mathrm{~h}$ and dried to constant mass using a centrifugal evaporator (Heto Maxi Dry Plus).

\section{Cholesterol assimilation experiments}

Individual colonies from Turbo yeast (S. cerevisiae) and MYA-796 (S. boulardii) agar plates were used to inoculate $10 \mathrm{~mL}$ volumes of ${ }_{\mathrm{glc}} \mathrm{YM}^{+ \text {chol }}$ media. These starter cultures (3 replicates per yeast species) were maintained at $37^{\circ} \mathrm{C}$ for $48 \mathrm{~h}$ in static (no agitation) $30 \mathrm{~mL}$ sterilin vials to attain low-oxygen conditions. At $t_{48} h$, cell pellets were harvested by centrifugation and washed three times with sterile water prior to sterol extraction, derivatisation and analysis using gas chromatography-mass spectrometry (GC-MS).

\section{GC-MS sterol analysis}

Washed cell pellets from cultures grown using YPD, GJ $+{ }_{\mathrm{t}}$ fosEp and ${ }_{\text {glc }} \mathrm{YM}^{+ \text {chol }}$ were resuspended in 7:3 methanol:water containing $18 \%(\mathrm{w} / \mathrm{v})$ potassium hydroxide and $0.1 \%(\mathrm{w} / \mathrm{v})$ pyrogallol and heated at $90^{\circ} \mathrm{C}$ for $2 \mathrm{~h}$.
Non-saponifiable sterols were extracted into glass HPLC vials using $3 \times 2 \mathrm{~mL}$ volumes of hexane. Extracts were evaporated to dryness using a centrifugal evaporator (Heto Maxi Dry Plus) and derivatised using $100 \mu \mathrm{L} \mathrm{N}$, O-bis(trimethylsilyl)trifluoroacetamide and trimethylchlorosilane (BSTFA-TMCS [99:1]) and $50 \mu \mathrm{L}$ anhydrous pyridine at $70^{\circ} \mathrm{C}$ for $2 \mathrm{~h}$.

Trimethylsilyl (TMS)-derivatised sterols were analyzed using a 7890A GC-MS system (Agilent Technologies) with a DB-5MS fused silica column $(30 \mathrm{~m} \times 0.25 \mathrm{~mm} \times 0.25 \mu \mathrm{m}$ film thickness; J\&W Scientific). The oven temperature was initially held at $70^{\circ} \mathrm{C}$ for $4 \mathrm{~min}$, then increased at $25^{\circ} \mathrm{C} \mathrm{min} \mathrm{min}^{-1}$ to a final temperature of $280^{\circ} \mathrm{C}$, which was held for a further $25 \mathrm{~min}$. Samples were analyzed in splitless mode ( $1 \mu \mathrm{L}$ injection volume) using helium carrier gas, electron impact ionization (ion source temperature of $150^{\circ} \mathrm{C}$ ) and scanning from $\mathrm{m} / \mathrm{z} 40$ to 850 . GC-MS data files were analysed using MSD Enhanced ChemStation software (Agilent Technologies) to determine sterol profiles for all isolates and for derivation of integrated peak areas. Sterols were identified by reference to retention times and mass fragmentation patterns for known standards.

\section{Results}

Results from the present study demonstrate the potential to co-produce bioethanol and probiotic yeast biomass from grass juice feedstock and identify avenues for process development and application in rural birefinery settings.

Pre-treatment of grass juice (GJ) feedstock with the soluble, truncated core domain of Lactobacillus paracasei $\beta$-fructosidase ( ${ }_{\mathrm{t}}$ fosEp) purified from recombinant Escherichia coli (Martel et al. 2010) resulted in the complete hydrolysis of non-fermentable fructan moieties (Figure 1). The total monosaccharide (glucose and fructose) content of GJ $+{ }_{t}$ fosEp $\left(73.31[ \pm 0.67] \mathrm{mg} \mathrm{mL}^{-1}\right.$ ) was over two-fold higher than that of untreated GJ (30.39

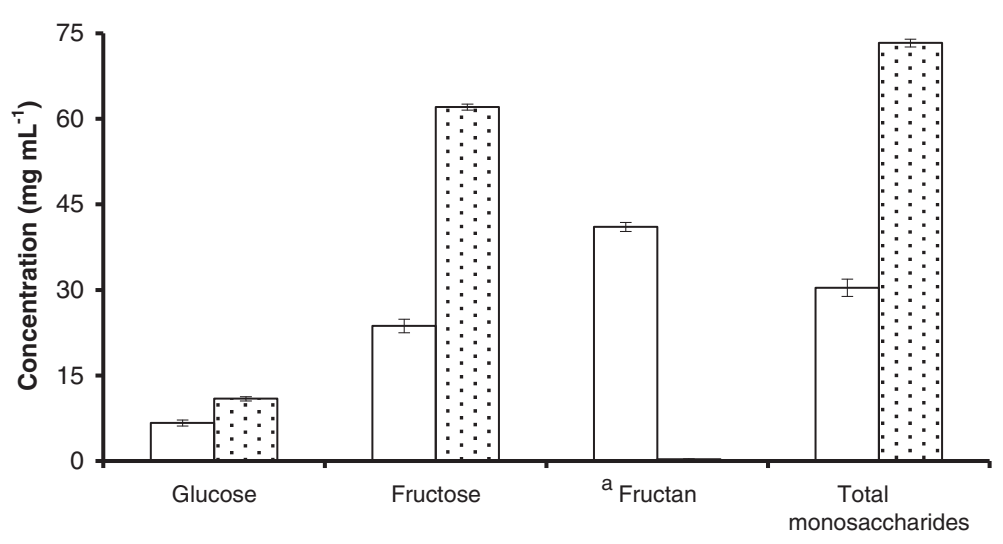

Figure 1 Mean $[ \pm S . D]$ glucose, fructose and fructan concentrations in untreated GJ (open bars) and GJ + ,fosEp (filled bars). ${ }^{\text {a }}$ Fructan $=$ polyfructose. 
Table 1 Mean [ \pm S.D] growth parameters for Turbo yeast and MYA-796 grown on enzyme-pretreated grass juice (GJ + tosEp)

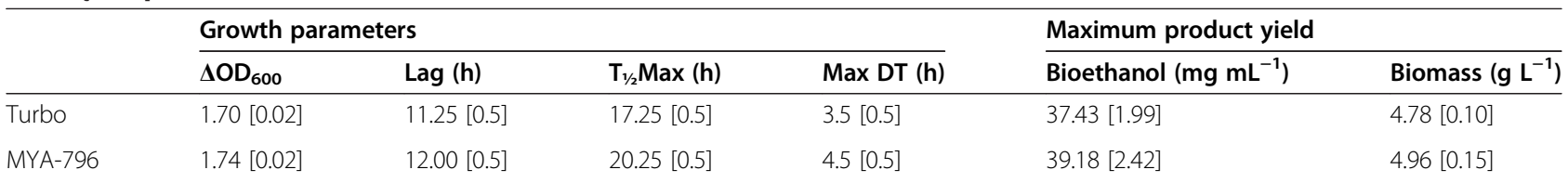

$\Delta \mathrm{OD}_{600}=$ maximum - minimum optical density reading (at $600 \mathrm{~nm}$ ); Lag phase = length of time population remains at $<10 \%$ of maximum OD; $\mathrm{T}_{1 / 2} \mathrm{Max}=$ time taken to achieve half maximal population growth (maximum OD - minimum OD $\times 0.5$ ); Max DT = maximum observed doubling time.

$\left.[ \pm 1.51] \mathrm{mg} \mathrm{mL}^{-1}\right)$; the sucrose content of both was negligible $\left(0.60[ \pm 0.06] \mathrm{mg} \mathrm{mL}^{-1}\right)$. Grass juice contains smaller amounts of other sugars (e.g., galactooligosaccharides and maltosaccharides) in addition to proteins which can also be used for fermentation and growth; non-fermentable carbohydrates (i.e., lignin, cellulose and hemicellulose) are found in grass pulp and the fibrous biomass fraction (Charlton et al. 2009). GJ $+{ }_{\mathrm{t}}$ fosEp was found to support optimal yeast growth, bioethanol and biomass production and was consequently employed as the feedstock for all experimental work reported in the present study.

The growth parameters determined for $S$. cerevisiae (Turbo yeast) and $S$. boulardii (MYA-769) were closely comparable (Table 1 and Figure 2) indicating that the composition of GJ $+{ }_{\mathrm{t}}$ fosEp did not inhibit the growth of either yeast. The maximum bioethanol and biomass product yields for Turbo $\left(37.43[ \pm 1.99] \mathrm{mg}\right.$ ethanol $\mathrm{mL}^{-1}$ and $4.78[ \pm 0.10] \mathrm{g}$ dry weight $\mathrm{L}^{-1}$ ) and MYA-769 (39.18 [ \pm 2.42$] \mathrm{mg}$ ethanol $\mathrm{mL}^{-1}$ and $4.96[ \pm 0.15] \mathrm{g}$ dry weight $\mathrm{L}^{-1}$ ) were also very similar.

Microscope observations revealed that the two yeasts exhibited different growth morphologies (Figure 3). Turbo cultures were characterised by round solitary blastoconidia and normal cellular budding (Figure 3A) while MYA-769 cultures comprised a mixture of yeast-like, elongated and psuedohyphal growth forms (Figure 3B).

Results from cholesterol uptake experiments (Table 2 and Figures 4 and 5) indicate that, under oxygen-limited conditions and at a growth temperature compatible with that of the human body $\left(37^{\circ} \mathrm{C}\right)$ MYA-769 assimilated more cholesterol than Turbo (Table 2 and Figure 5).

\section{Discussion}

\section{Bioethanol and biomass}

S. cerevisiae has traditionally been used in food production, biotechnology, brewing and biofuel industries; however, the bioethanol and biomass production observed in the present study highlights the potential to utilise $S$. boulardii for industrial ethanol fermentation processes (Gurgu et al. 2011). That GJ $+{ }_{\mathrm{t}}$ fosEp is a suitable feedstock for yeast biofermentations is evidenced by the sterol composition of both yeast species following growth on standard YPD media and GJ $+{ }_{\text {t}}$ fosEp (Table 2 and Figure 4). Neither yeast was affected by perturbations in ergosterol biosynthesis; ergosterol is an essential yeast membrane sterol needed to maintain membrane viability and healthy growth (Daum et al. 1998). Morphological differences were observed when Turbo and MYA-769 were grown using both GJ $+{ }_{\mathrm{t}}$ fosEp and standard YPD media suggesting that the psuedohyphal growth of MYA-769 (Figure 3) is a typical strain characteristic and not a response to nutrient limitation; nutrient limitation is understood to be a prerequisite for filamentous growth in wild-type S. cerevisiae (Gimeno et al. 1992).

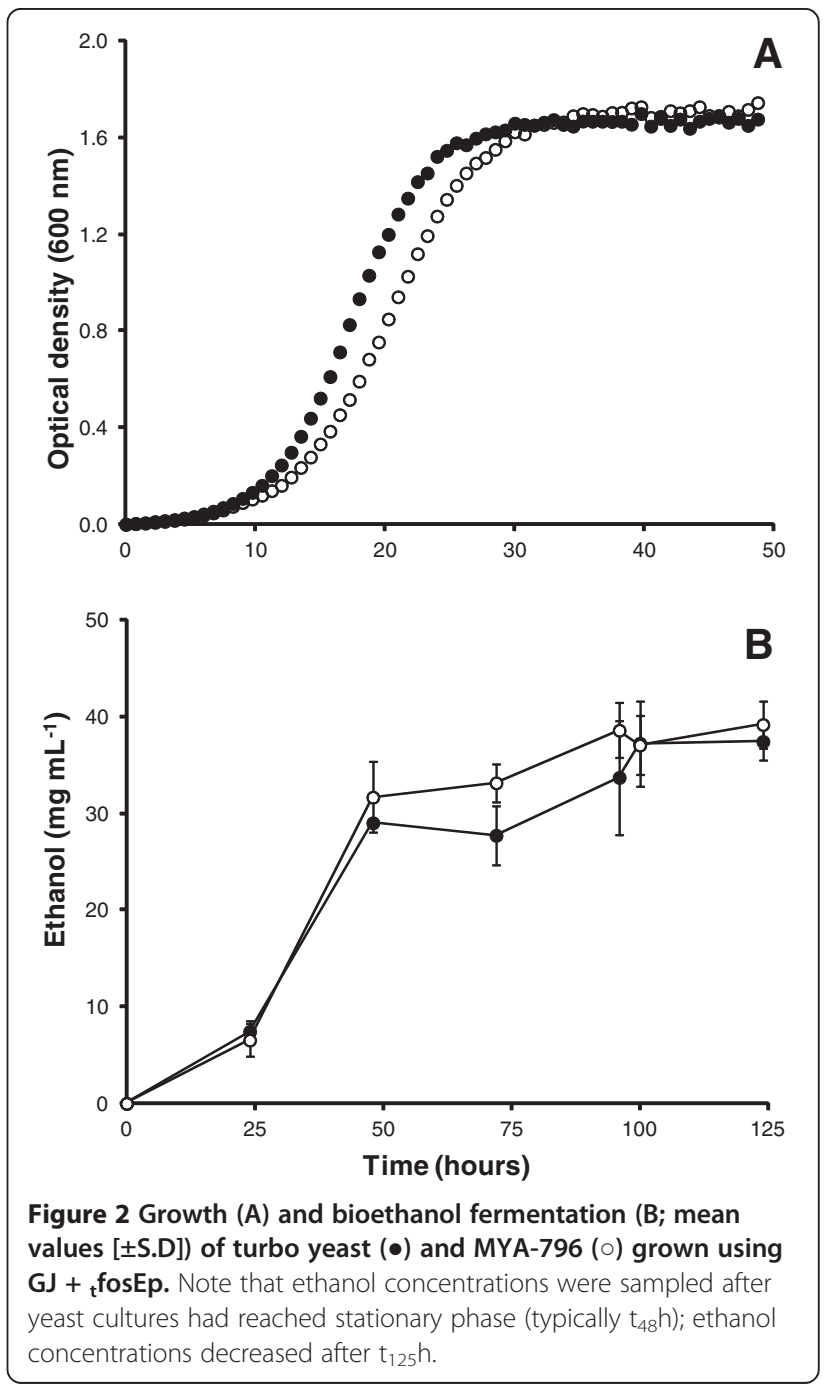




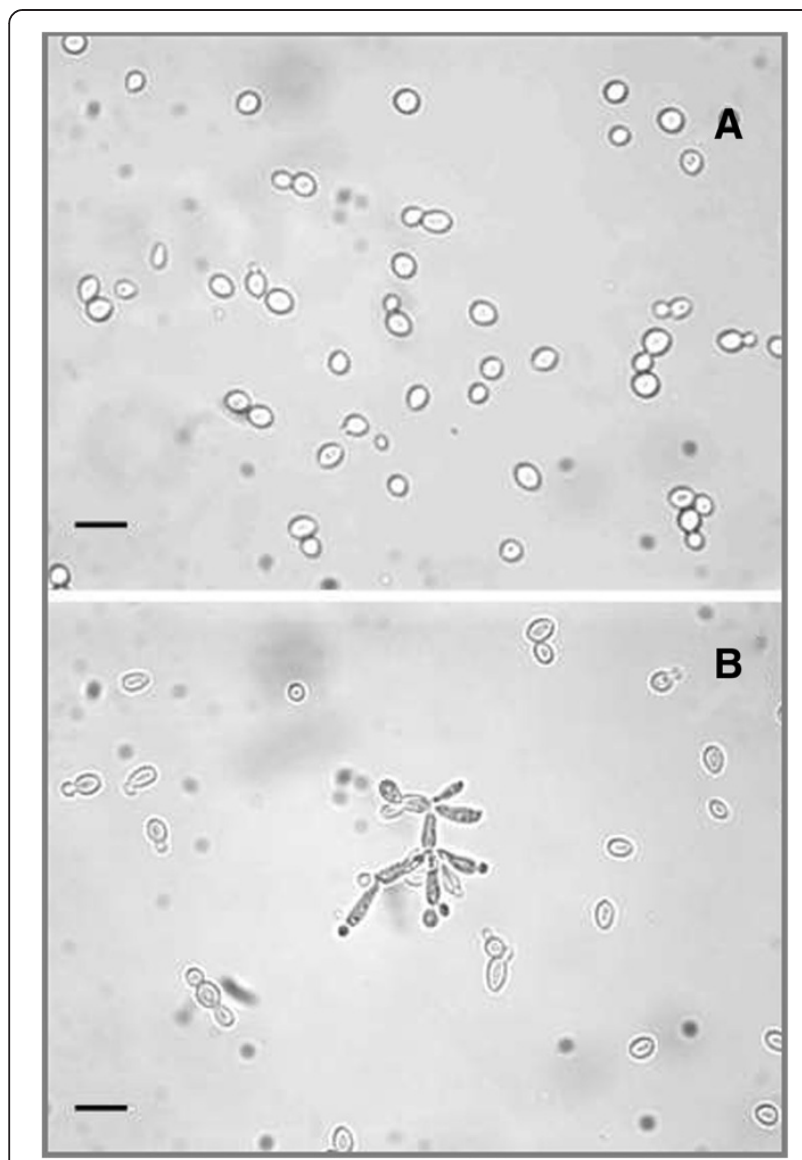

Figure $\mathbf{3}$ Cell morphology of yeast strains. $\mathbf{A}$ =yeast-like growth of turbo (S. cerevisiae) showing solitary blastoconidia and normal budding; B = pseudohyphal growth of MYA-796 (S. boulardii). Scale bars represent $15 \mu \mathrm{m}$.

S. boulardii is reported to possess an enhanced ability for pseudohyphal switching and is understood to survive better at low $\mathrm{pH}$ than other strains of $\mathrm{S}$. cerevisiae (Edwards-Ingram et al. 2007).

Given these morphological and physiological characteristics, $S$. boulardii presents itself as an attractive microorganism for biotechnology and industrial applications where flocculent and sedimenting strains of $S$. cerevisiae are particularly valuable (Kida et al. 1990;
Seong et al. 2006). A flocculation mutant of Candida glabrata, another species showing genetic relatedness to S. cerevisiae (Roetzer et al. 2011), has been identified as a potentially useful strain for bioethanol production because of its growth at higher temperatures (Watanabe et al. 2009).

\section{Cholesterol assimilation}

Research and commercial interest surrounds the biotherapeutic properties of different yeasts (Foligne et al. 2010) and those with cholesterol-lowering activity have attracted specific attention (Chen et al. 2010; Psomas et al. 2003). S. cerevisiae is already known to sequester extracellular cholesterol under anaerobic conditions (Lorenz et al. 1986); however, results from the present study indicate cholesterol uptake by $S$. boulardii (strain MYA-769) is superior. In view of the impetus towards lowering cholesterol through dietary modifications and speculation that probiotic yeast could provide a means to lower serum cholesterol (Chen et al. 2010; Krasowska et al. 2007) work to characterise cholesterol uptake in the host environment using a wider number of strains is now required. Phytosterols were not detectable in the sterol chromatograms for Turbo yeast or MYA-796 grown using GJ $+{ }_{\text {t }}$ fosEp (Table 2 and Figure 4), and indeed the sterol content of GJ was negligible; however, we did find residual ryegrass pulp, a by-product of the grass juice extraction process, to be rich in plant sterols (data not shown). The potential to extract phytosterols from ryegrass and alternative plant biomass feedstock requires consideration not least because diet supplementations containing plant sterols could offer protection against a variety of chronic ailments including cardiovascular diseases, obesity, diabetes, and cancer (Bradford and Awad 2007).

\section{Applications for yeast biomass}

Given legislation restricting the addition of antibiotics to animal feed (Seo et al., 2010) the potential to market food-grade yeast biomass and/or utilise it in a rural biorefinery setting is important. The use of $S$. boulardii for treatment of human gastrointestinal disorders is well documented (Buts 2009; Vandenplas et al. 2009;

Table 2 Mean [ \pm S.D] cellular sterol composition (\%) of turbo yeast and MYA-796

\begin{tabular}{|c|c|c|c|c|c|c|c|c|c|c|}
\hline & \multicolumn{10}{|c|}{ Sterol composition (\%) } \\
\hline & \multicolumn{2}{|c|}{ Zymosterol } & \multicolumn{2}{|l|}{ Ergosterol } & \multicolumn{2}{|l|}{ Lanosterol } & \multicolumn{2}{|c|}{${ }^{\mathrm{a}}$ Intermediates } & \multicolumn{2}{|c|}{ Cholesterol } \\
\hline & Turbo & MYA-769 & Turbo & MYA-769 & Turbo & MYA-769 & Turbo & MYA-769 & Turbo & MYA-769 \\
\hline YPD & $17.92[0.38]$ & $17.79[0.49]$ & $61.71[3.29]$ & $61.91[1.39]$ & $5.93[1.65]$ & $8.06[0.59]$ & $14.45[2.02]$ & $12.25[1.49]$ & - & - \\
\hline GJ $+{ }_{t}$ fosEp & $15.53[2.80]$ & $12.31[0.10]$ & $67.31[0.49]$ & $61.86[1.10]$ & $5.90[0.09]$ & $9.31[0.76]$ & $11.26[3.20]$ & $16.52[0.23]$ & - & - \\
\hline $\mathrm{glc}_{\mathrm{YM}}^{\text {+chol }}$ & $5.7[0.78]$ & $1.6[0.41]$ & 26.9 [1.27] & $12.2[2.12]$ & $35.7[0.74]$ & $38.2[3.64]$ & $27.10[1.79]$ & $27.30[2.05]$ & $4.6[0.48]^{\mathbf{b}}$ & $20.7[0.96]^{\mathbf{b}}$ \\
\hline
\end{tabular}

The most abundant sterol in each experiment is emboldened. ${ }^{a}=$ sum of all minor sterol intermediates (each comprising $<5 \%$ of total cellular sterol fraction);

${ }^{b}=$ exogenously supplied cholesterol; Strikethrough $=$ not detected. 

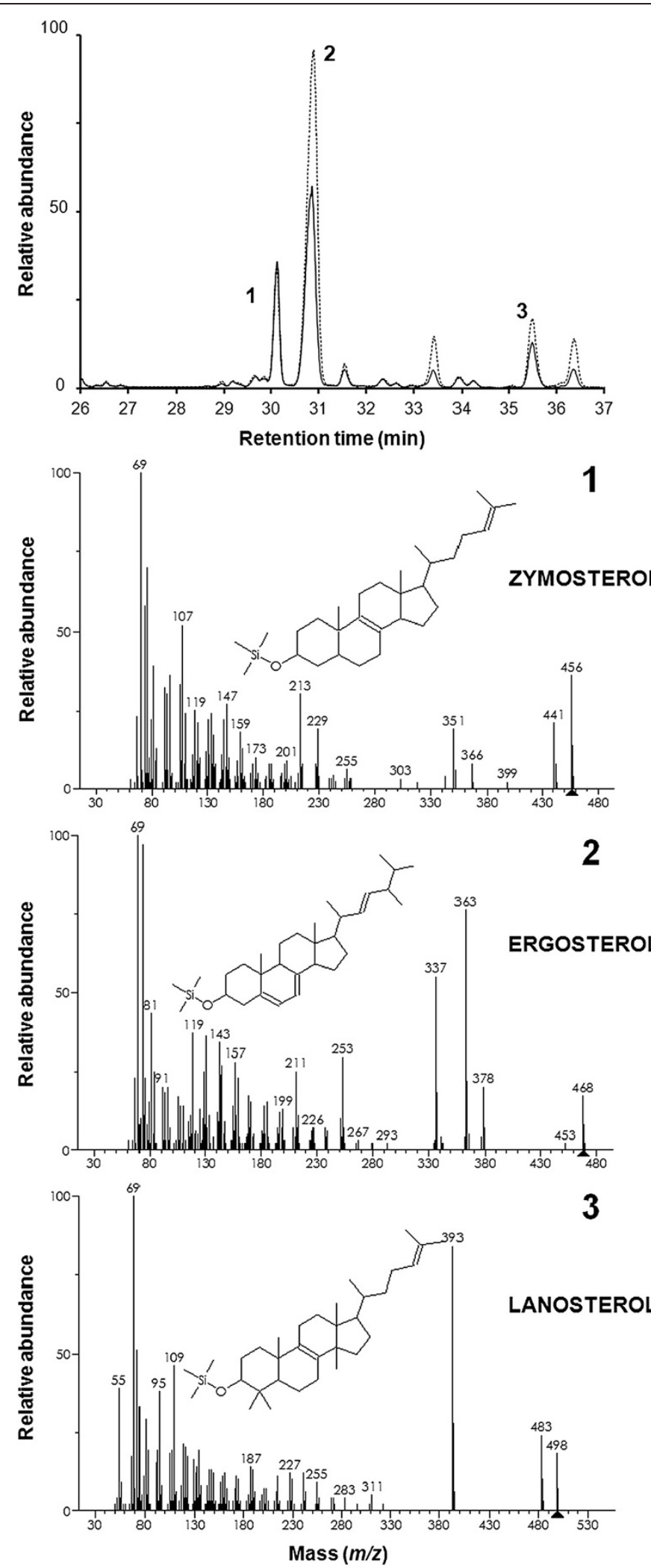

Figure 4 Sterol composition. Overlay of GC-MS sterol chromatograms for turbo yeast (unbroken trace) and MYA-796 (broken trace) grown on GJ + ${ }_{t}$ fosEp. Diagnostic fragmentation spectra for $\mathbf{1}$ ) zymosterol, 2) ergosterol and 3) lanosterol are shown; note the presence of minor sterol intermediates (retention times 31.5-34.5 min and $36.5 \mathrm{~min}$ ). 


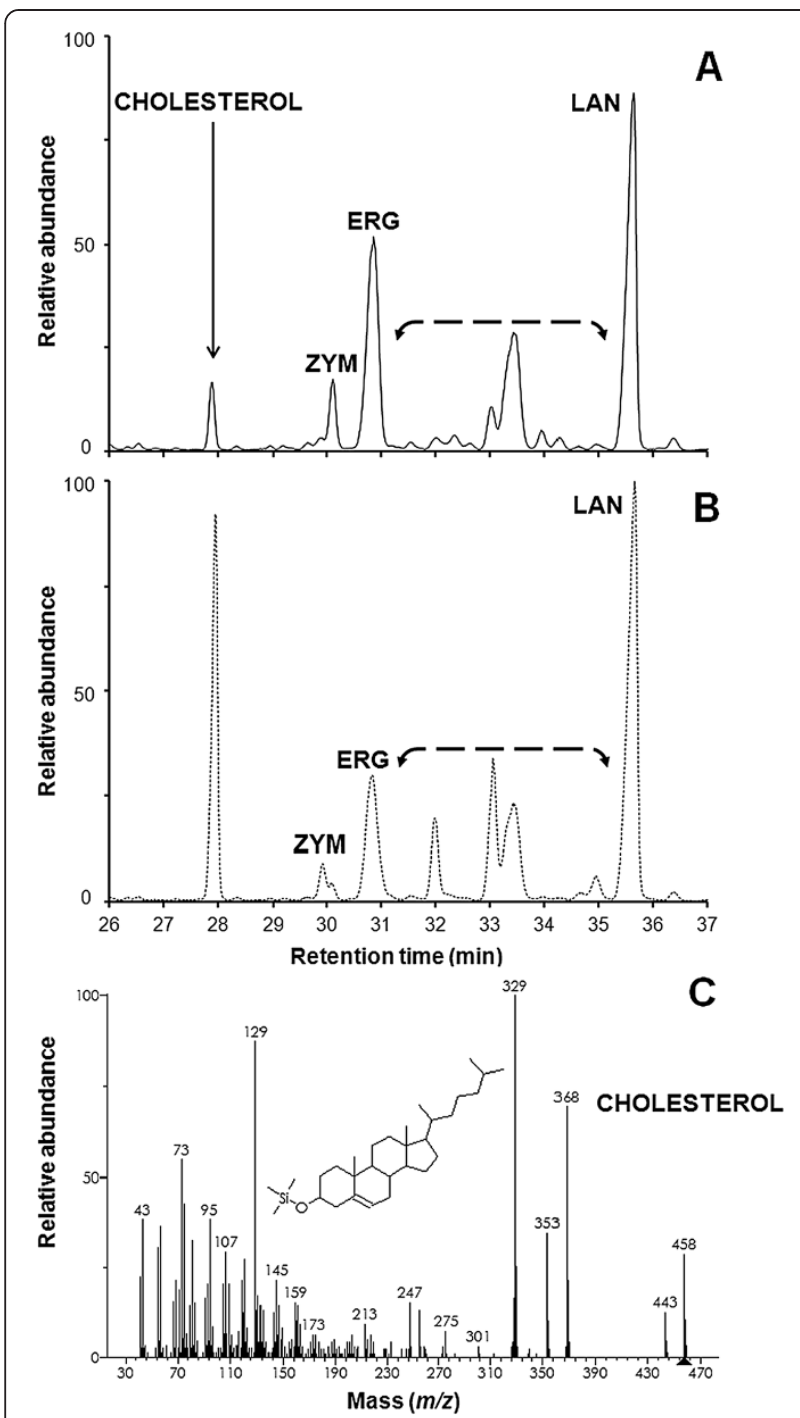

Figure $\mathbf{5}$ Cholesterol assimilation experiments. Overlay of GC-MS sterol chromatograms for $\mathbf{A}$ ) turbo yeast (unbroken trace) and B) MYA-796 (broken trace) grown on glc YM $^{\text {+chol }}$. The diagnostic fragmentation spectrum for cholesterol is shown (C). Note the increased abundance of minor sterol intermediates (bracketed arrow) relative to cultures grown on GJ + ${ }_{\text {fosEp }}$ and YPD media.

Zanello et al. 2009) and studies indicate that probiotic yeast could also be administered as a direct-fed microbial to improve livestock quality (Collier et al. 2010; Keyser et al. 2007). The effects of dietary yeast (S. cerevisiae) autolysate on poultry health have also been documented (Yalçin et al. 2012). Finally, there is emerging evidence to show that dietary yeast supplementations could mitigate ruminant enteric methane emissions (Cottle et al. 2011; Lila et al. 2004). Methane is the second most important greenhouse gas and considering the importance of ruminant livestock, probiotic administration could offer an economically feasible way of reducing ruminant $\mathrm{CH}_{4}$ production while improving productivity (Shibata and Terada 2010).
In conclusion, rural biorefineries have been identified as a potential means to facilitate social and economic regeneration in regions where a low GDP affects communities (Charlton et al. 2009). Here we demonstrate the possibility of generating bioethanol and probiotic yeast biomass from agriculturally-sourced grass juice. Breeding for bio-ethanol production using L. perenne L. with higher water-soluble carbohydrate content is already underway in the United Kingdom (Farrar et al. 2012) and results from the present study highlight further opportunities for integrated microbial biotechnology and large scale biorefining using high sugar perennial ryegrasses (Charlton et al. 2009; Martel et al. 2010; Martel et al. 2011). The experiments described can be a base towards extraction of maximum value from grass as proteins and chlorophyll are some of the other products that can be envisaged. The grass cellulosic fibre could also be fermented after appropriate enzymological and process treatments. Increased content of water soluble carbohydrates in breeding processes and engineering solutions to concentrate the juice to generate higher concentrations of bioethanol for distillation are also avenues that need to be explored. Finally it is evident $S$. boulardii could be used in other bioethanol processes if a use for biomass on that scale was desirable as in reducing methane emissions.

\section{Competing interests}

The authors declare that they have no competing interests.

\section{Authors' contributions}

$\mathrm{CMH}$ designed and undertook the growth studies and conceived and drafted the manuscript. EJL carried out the sugar assays. ISD and DEK participated in the design of the study and written work. SLK conceived the study, and participated in its design and coordination and helped to draft the manuscript. All authors read and approved the final manuscript.

\section{Authors' information}

EJL undertook experimental work at Swansea University, his current contact address is now: School of Chemistry, Cardiff University, Main Building, Park Place, Cardiff, CF10 3AT, Wales, UK.

\section{Acknowledgements}

We thank Marcus Hull for technical support. Funding for this study was provided by the Biotechnology and Biological Sciences Research Council (2/E13805) and the BEACON Convergence project supported by Welsh Government and the European Regional Development Fund (ERDF) of the European Union. Analytical facilities were provided by the EPSRC National Mass Spectrometry Service Centre (Swansea University, UK).

\section{Author details}

'Institute of Life Science, College of Medicine, Swansea University, Swansea SA2 8PP, Wales, UK. ${ }^{2}$ Institute of Biological, Environmental \& Rural Sciences, Aberystwyth University, Gogerddan, Aberystwyth SY23 3EE, Wales, UK.

Received: 2 April 2014 Accepted: 4 August 2014

Published online: 01 September 2014

\section{References}

Bradford PG, Awad AB (2007) Phytosterols as anticancer compounds. Mol Nutr Food Res 51(2):161-170

Buts J-P (2009) The probiotic Saccharomyces boulardii upgrades intestinal digestive functions by several mechanisms. Acta Gastroenterol Belg 72(2):274-276 
Charlton A, Elias R, Fish S, Fowler P, Gallagher J (2009) The biorefining opportunities in Wales: Understanding the scope for building a sustainable, biorenewable economy using plant biomass. Chem Eng Res Des 87(9A):1147-1161

Chen L-S, Ma Y, Maubois JL, He SH, Chen LJ, Li HM (2010) Screening for the potential probiotic yeast strains from raw milk to assimilate cholesterol. Dairy Sci Technol 90(5):537-548

Collier CT, Carroll JA, Ballou MA, Starkey JD, Sparks JC (2010) Oral administration of Saccharomyces cerevisiae boulardii reduces mortality associated with immune and cortisol responses to Escherichia coli endotoxin in pigs. J Anim Sci 89(1):52-58

Cottle DJ, Nolan JV, Wiedemann SG (2011) Ruminant enteric methane mitigation: a review. Anim Prod Sci 51(6):491-514

Daum G, Lees ND, Bard M, Dickson R (1998) Biochemistry, cell biology and molecular biology of lipids of Saccharomyces cerevisiae. Yeast 14(16):1471-1510

Edwards-Ingram LC, Gent ME, Hoyle DC, Hayes A, Stateva LI, Oliver SG (2004) Comparative genomic hybridization provides new insights into the molecular taxonomy of the Saccharomyces sensu stricto complex. Genome Res 14(6):1043-1051

Edwards-Ingram L, Gitsham P, Burton N, Warhurst G, Clarke I, Hoyle D, Oliver SG, Stateva L (2007) Genotypic and physiological characterization of Saccharomyces boulardii, the probiotic strain of Saccharomyces cerevisiae. Appl Environ Microb 73(8):2458-2467

Farrar K, Bryant DN, Turner L, Gallagher JA, Thomas A, Farrell M, Humphreys MO, Donnison IS (2012) Breeding for bio-ethanol production in Lolium perenne L.: Association of allelic variation with high water-soluble carbohydrate content. abbreviation. Bioenerg Res 5(1):149-157

Foligne B, Dewulf J, Vandekerckove P, Pignede G, Pot B (2010) Probiotic yeasts: Anti-inflammatory potential of various non-pathogenic strains in experimental colitis in mice. World J Gastroenterol 16(17):2134-2145

Gimeno CJ, Ljungdahl PO, Styles CA, Fink GR (1992) Unipolar cell divisions in the yeast Saccharomyces cerevisiae lead to filamentous growth - Regulation by starvation and Ras. Cell 68(6):1077-1090

Gurgu L, Lafraya A, Polaina J, Marin-Navarro J (2011) Fermentation of cellobiose to ethanol by industrial Saccharomyces strains carrying the beta-glucosidase gene (BGL1) from Saccharomycopsis fibuligera. Bioresour Technol 102(8):5229-5236

Keyser SA, McMeniman JP, Smith DR, MacDonald JC, Galyean ML (2007) Effects of Saccharomyces cerevisiae subspecies boulardii CNCM I-1079 on feed intake by healthy beef cattle treated with florfenicol and on health and performance of newly received beef heifers. J Anim Sci 85(5):1264-1273

Kida K, Asano SI, Yamadaki M, Iwasaki K, Yamaguchi T, Sonoda Y (1990) Ethanol-production by flocculating yeast.4. Continuous high-ethanol fermentation from cane molasses by a flocculating yeast. J Ferment Bioeng 69(1):39-45

Krasowska A, Kubik A, Prescha A, Lukaszewicz M (2007) Assimilation of omega 3 and omega 6 fatty acids and removing of cholesterol from environment by Saccharomyces cerevisiae and Saccharomyces boulardii strains. J Biotechnol 131(2):S63-S64

Kyazze G, Dinsdale R, Hawkes FR, Guwy AJ, Premier GC, Donnison IS (2008) Direct fermentation of fodder maize, chicory fructans and perennial ryegrass to hydrogen using mixed microflora. Bioresour Technol 99(18):8833-8839

Leistritz FL, Hodur NM (2008) Biofuels: a major rural economic development opportunity. Biofuel Bioprod Bior Biofpr 2(6):501-504

Lila ZA, Mohammed N, Yasui T, Kurokawa Y, Kanda S, Itabashi H (2004) Effects of a twin strain of Saccharomyces cerevisiae live cells on mixed ruminal microorganism fermentation in vitro. J Anim Sci 82(6):1847-1854

Lorenz RT, Rodriguez RJ, Lewis TA, Parks LW (1986) Characteristics of sterol uptake in Saccharomyces cerevisiae. J Bacteriol 167(3):981-985

Martel CM, Warrilow AGS, Jackson CJ, Mullins JGL, Togawa RC, Parker JE, Morris MS, Donnison IS, Kelly DE, Kelly SL (2010) Expression, purification and use of the soluble domain of Lactobacillus paracasei beta-fructosidase to optimise production of bioethanol from grass fructans. Bioresour Technol 101(12):4395-4402

Martel CM, Parker JE, Jackson CJ, Warrilow AGS, Rolley N, Greig C, Morris SM, Donnison IS, Kelly DE, Kelly SL (2011) Expression of bacterial levanase in yeast enables simultaneous saccharification and fermentation of grass juice to bioethanol. Bioresour Technol 102(2):1503-1508

Moyad MA (2008) Brewer's/baker's yeast (Saccharomyces cerevisiae) and preventive medicine: Part II. Urol Nurs 28(1):73-75

Psomas El, Fletouris DJ, Litopoulou-Tzanetaki E, Tzanetakis N (2003) Assimilation of cholesterol by yeast strains isolated from infant feces and Feta cheese. J Dairy Sci 86(11):3416-3422
Roetzer A, Gabaldon T, Schueller C (2011) From Saccharomyces cerevisiae to Candida glabrata in a few easy steps: important adaptations for an opportunistic pathogen. FEMS Microbiol Lett 314(1):1-9

Seo JK, Kim S-W, Kim MH, Upadhaya SD, Kam DK, Ha JK (2010) Direct-fed microbials for ruminant animals. Asian Aust J Anim Sci 23(12):1657-1667

Seong KT, Katakura Y, Ninomiya K, Bito Y, Katahira S, Kondo A, Ueda M, Shioya S (2006) Effect of flocculation on performance of arming yeast in direct ethanol fermentation. Appl Microbiol Biotechnol 73(1):60-66

Sharma HSS, Lyons G, McRoberts C (2011) Biorefining of perennial grasses: A potential sustainable option for Northern Ireland grassland production. Chem Eng Res Des 89(11A):2309-2321

Shibata M, Terada F (2010) Factors affecting methane production and mitigation in ruminants. Anim Sci J 81(1):2-10

Vandenplas Y, Brunser O, Szajewska H (2009) Saccharomyces boulardii in childhood. J Pediatr 168(3):253-265

Wang J-M, Zhang T, Chi Z, Liu G-L, Chi Z-M (2011) 18S rDNA integration of the exo-inulinase gene into chromosomes of the high ethanol producing yeast Saccharomyces sp W0 for direct conversion of inulin to bioethanol. Biomass Bioenerg 35(7):3032-3039

Watanabe I, Nakamura T, Shima J (2009) Characterization of a spontaneous flocculation mutant derived from Candida glabrata: A useful strain for bioethanol production. J Biosci Bioeng 107(4):379-382

Yalçin S, Uzunoglu K, Duyum HM, Eltan O (2012) Effects of dietary yeast autolysate (Saccharomyces cerevisiae) and black cumin seed (Nigella sativa L.) on performance, egg traits, some blood characteristics and antibody production of laying hens. Livest Sci 145(1-3):13-20

Zanello G, Meurens F, Berri M, Salmon H (2009) Saccharomyces boulardii effects on gastrointestinal diseases. Curr Issues Mol Biol 11:47-58

Zhang T, Chi Z, Chi Z, Parrou J-L, Gong F (2010) Expression of the inulinase gene from the marine-derived Pichia guilliermondii in Saccharomyces sp W0 and ethanol production from inulin. Microbial Biotech 3(5):576-582

doi:10.1186/s13568-014-0064-5

Cite this article as: Hull et al:: Co-production of bioethanol and probiotic yeast biomass from agricultural feedstock: application of the rural biorefinery concept. AMB Express 2014 4:64.

\section{Submit your manuscript to a SpringerOpen ${ }^{\circ}$ journal and benefit from:}

- Convenient online submission

- Rigorous peer review

- Immediate publication on acceptance

- Open access: articles freely available online

- High visibility within the field

- Retaining the copyright to your article

Submit your next manuscript at $>$ springeropen.com 